\title{
Reaction Mechanism and Kinetics of Boron Removal from Molten Silicon by $\mathrm{CaO}-\mathrm{SiO}_{2}-\mathrm{CaCl}_{2}$ Slag Treatment
}

\author{
Ye Wang ${ }^{1} \cdot$ Kazuki Morita ${ }^{1}$
}

Published online: 1 April 2015

(C) The Minerals, Metals \& Materials Society (TMS) 2015

\begin{abstract}
The mechanism by which $\mathrm{B}$ is removed from $\mathrm{Si}$ to a molten $\mathrm{CaO}-\mathrm{SiO}_{2}-\mathrm{CaCl}_{2}$ slag, and its subsequent evaporation to a gas phase at $1723 \mathrm{~K}$, has been evaluated with a view to optimize the production of solar-grade $\mathrm{Si}$. By assuming a diffusion model for the transfer of $\mathrm{B}$ from $\mathrm{Si}$ to molten slag, and its evaporation to a gas phase, the diffusion coefficient of B in slag was investigated using the tube-molten pool method. The mass transfer coefficients of $\mathrm{B}$ in slag were also measured and calculated according to Fick's law. Through this, it was found that the rate-limiting step of B removal in the slag refining process is controlled by $\mathrm{B}$ transfer from both the slag interface and surface. Of these, however, it is the former that has the greater influence, as the slag boundary layers in the interface are thicker than those at the surface.
\end{abstract}

Keywords Solar-grade silicon · Slag refining · Boron removal - Mass transfer coefficient - Diffusion coefficient

\section{Introduction}

The availability of abundant and low-cost solar-grade $\mathrm{Si}$ (SOG-Si) feedstock is essential to support the widespread use of solar cells; and indeed, there has been great progress in reducing energy consumption in the modified Siemens and fluidized bed reactor processes of fabricating SOG-Si.

Ye Wang

280405702@qq.com; wangye@iis.u-tokyo.ac.jp

1 Department of Materials Engineering, The University of Tokyo, 4-6-1 Bunkyou, Tokyo 113-8656, Japan
However, the potential for cost reduction in these processes is limited by the low productivity of $\mathrm{Si}$ and the amount of chemical energy required to convert metallurgical-grade $\mathrm{Si}$ (MG-Si) into gaseous compounds, not to mention the distillation, reduction, and deposition of these compounds as solid Si. A more cost-effective and energy-efficient alternative to produce SOG-Si is to use a metallurgical process, which provides sustainability and a number of benefits in terms of productivity and process cost. Metallurgical methods such as directional solidification [1-3], alloy refining [4-6], oxidation with plasma melting [7, 8], and vacuum melting $[9,10]$ have all been investigated; however, each has its own unique limitations that prevent the total removal of impurities. This is largely a result of the fact that the segregation coefficients of $\mathrm{B}$ and $\mathrm{P}$ are both close to 1 in molten $\mathrm{Si}$, meaning that they are not easily removed from the melt. Thus, in order to meet the strong demand for $\mathrm{Si}$ that is free of $\mathrm{B}$ and $\mathrm{P}$ via a low-cost process, the use of slag treatment as a method for the removal of $\mathrm{B}$ and $\mathrm{P}$ has received increased attention owing to its low cost and mass productivity.

In slag treatment, ternary slags of $\mathrm{CaO}-\mathrm{SiO}_{2}-\mathrm{CaCl}_{2}$ have been confirmed to be effective in removing $\mathrm{B}$, with a decrease in concentration from 150 to approximately 30 ppmw having been achieved at $1723 \mathrm{~K}\left(1450{ }^{\circ} \mathrm{C}\right)$ along with a B-removal efficiency as high as $86 \%$ [11]. Though this study provides a foundation, there is clearly a need for further research into the transportation kinetics of B from molten Si to molten slag, and its evaporation from slag to a gas phase. Thus, in the present study, a model for the mass transfer of B from molten Si through slag to the gas phase is first discussed. The diffusion coefficient of B in molten $\mathrm{Si}$ has been previously reported [12]; however, its diffusion coefficient in molten $\mathrm{CaO}-\mathrm{SiO}_{2}-\mathrm{CaCl}_{2}$ slag is still undefined. To address this, the diffusion coefficient of $\mathrm{B}$ in 
$\mathrm{CaO}-\mathrm{SiO}_{2}-\mathrm{CaCl}_{2}$ slag was investigated by the tube-molten pool method at $1723 \mathrm{~K}$. Finally, in order to investigate the rate controlling step and quantify the mass transfer of $B$ from molten $\mathrm{Si}$ through slag to the gas phase, the mass transfer coefficients of $B$ in the slag were also characterized.

\section{Experimental Procedure}

\section{Measuring the Diffusion Coefficient of B}

To measure the diffusion coefficient of B in molten slag, a graphite tube (length $=20 \mathrm{~mm}$, width $=15 \mathrm{~mm}$, height $=$ $12 \mathrm{~mm}$ ) was prepared with holes measuring $1.5 \mathrm{~mm}$. Next, $20 \mathrm{~g}$ of different $\mathrm{CaO}-\mathrm{SiO}_{2}-\mathrm{CaCl}_{2}$ slag system compositions were mixed in a graphite crucible and premelted in an induction furnace under vacuum, into which the graphite tube was immersed for $10 \mathrm{~min}$. A flow of Ar gas was then introduced to force the slag into the vacuum tube, which was finally lifted up and the furnace cooled to produce a slag-filled tube.

Diffusion coefficient experiments were carried out by first melting $30 \mathrm{~g}$ of the same slag composition with $100 \mathrm{ppmw}$ of $\mathrm{B}$ in a resistance furnace at $1723 \mathrm{~K}$ $\left(1450{ }^{\circ} \mathrm{C}\right.$ ) for $5 \mathrm{~min}$, into which the slag-filled tube was immersed for $20 \mathrm{~min}$. After the tube was removed, it was cut into portions (as shown in Fig. 1), and the slag was collected from the hole. The $\mathrm{B}$ concentration $\left(C_{\mathrm{B}}\right)$ of each portion $(l=2 \mathrm{~mm})$ of the tube was analyzed by inductively coupled plasma atomic emission spectrometry (ICP-AES).

\section{Measuring the Mass Transfer Coefficient of B}

The mass transfer coefficient was measured using a vertical $\mathrm{SiC}$ resistance furnace $(60 \mathrm{~mm}$ O.D., $53 \mathrm{~mm}$ I.D., $1000 \mathrm{~mm}$ length), the temperature of which was maintained at $1723 \pm 2 \mathrm{~K}$ using a PID controller (Fig. 2). For this, $3 \mathrm{~g}$ of Si containing $300 \mathrm{ppmw}$ of $\mathrm{B}$ was premelted at $1723 \mathrm{~K}$, and then, 3, 6, or $9 \mathrm{~g}$ of $30 \mathrm{~mol} \% \mathrm{CaO}-$ $23 \mathrm{~mol} \% \mathrm{SiO}_{2}-47 \mathrm{~mol} \% \mathrm{CaCl}_{2}$ slag was added and held at $1723 \mathrm{~K}$ under an Ar atmosphere for various periods of time. A NaOH solution was used to absorb any evaporated Cl-containing gas and after the experiment, the B concentration in the slag $\left[\left(\mathrm{B}^{3+}\right)_{b}\right]$ and $\mathrm{Si}\left([\mathrm{B}]_{\mathrm{b}}\right)$ was measured by ICP-AES.

\section{Results and Discussion}

\section{Diffusion Coefficient Measurement}

Figure 3 and Table 1 show the $\mathrm{B}$ distributions obtained with the four different slag compositions after $20 \mathrm{~min}$ at $1723 \mathrm{~K}$, in which it can be clearly seen that the concentration of $\mathrm{B}\left(C_{\mathrm{B}}\right)$ decreases from 100 to 0 ppmw with increasing distance from the end of the tube $(x)$.

If it is assumed that diffusion in the slag is dimensionally sufficiently long, then diffusion can be considered to begin at one edge of the slag, with the concentration remaining 0 at the other side. This type of diffusion can be expressed using the semi-infinite one-dimensional model, wherein the range of the diffusion distance, $x$, is $[0, \infty]$. At time $t=0$, it can be expressed as follows:
Fig. 1 Schematic of diffusion coefficient experiment

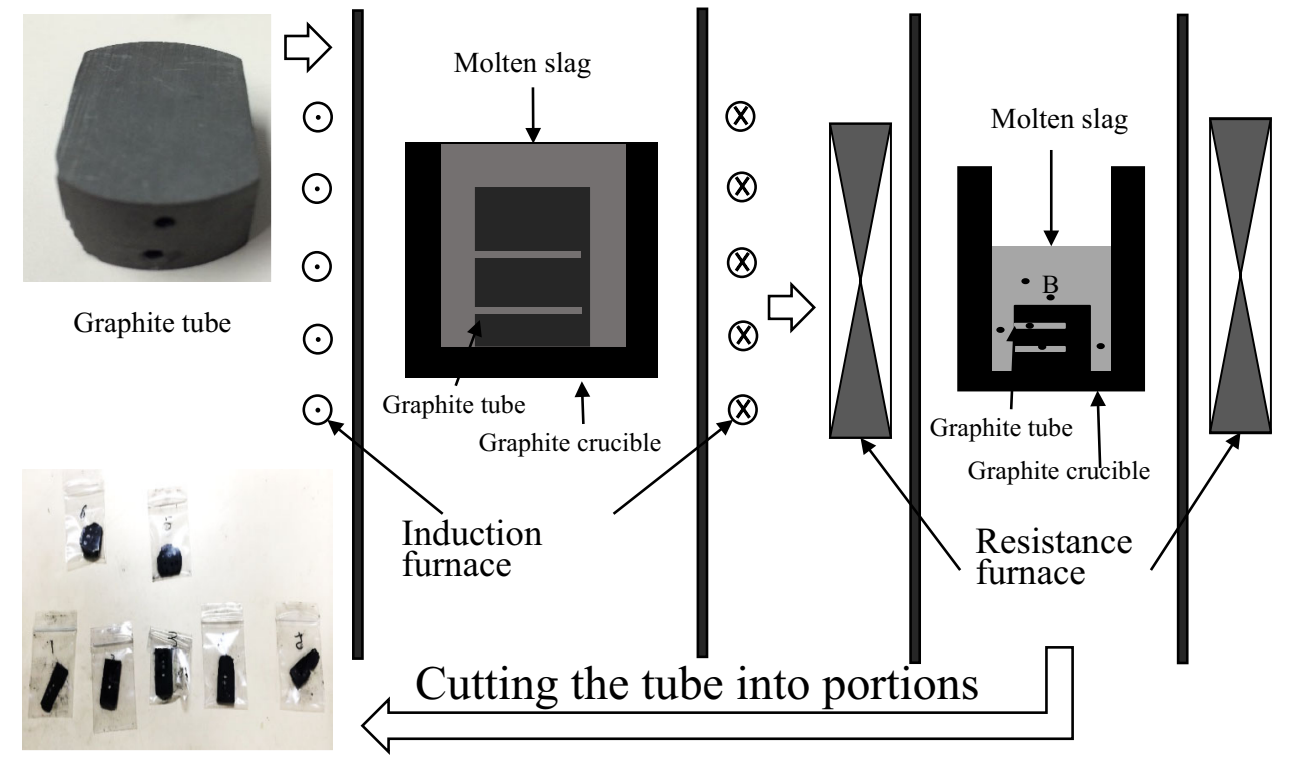




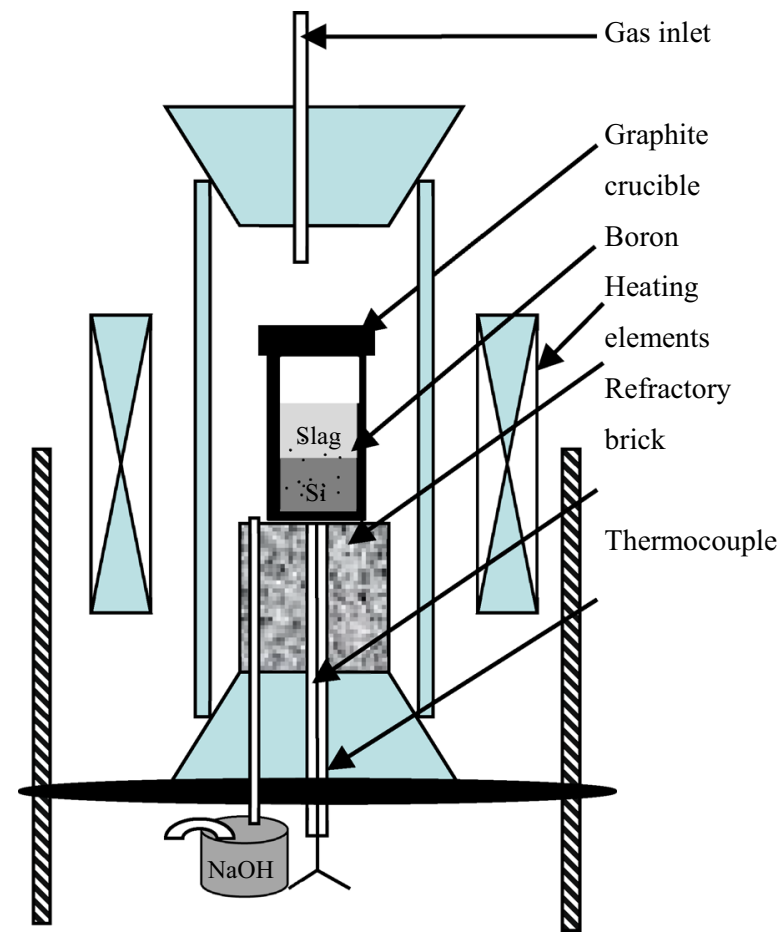

Fig. 2 Experimental set up of resistance furnace

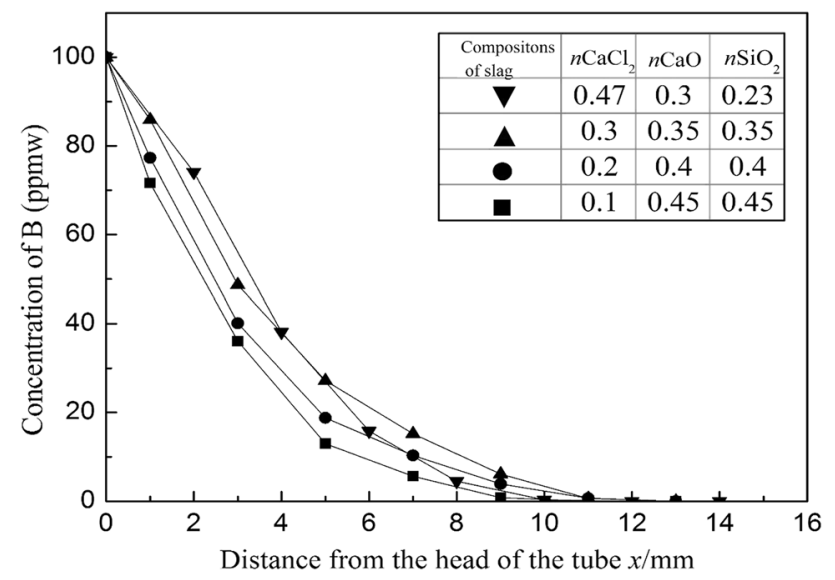

Fig. 3 Relationship between slag composition and the concentration of $\mathrm{B}$ at various positions

$$
\begin{aligned}
\frac{\partial C}{\partial t} & =\frac{\partial}{\partial x}\left(D \frac{\partial C}{\partial x}\right), C_{\mathrm{B}}(x, t) \\
& =C_{\mathrm{B}}^{0}-\left(C_{\mathrm{B}}^{0}-C_{0}\right) \operatorname{erf}\left(\frac{x}{2 \sqrt{D_{\mathrm{s}} t}}\right)
\end{aligned}
$$

Initial condition $C(x, 0)=C_{0}(t=0)$

Boundary condition $=\left\{\begin{array}{c}C(0, t)=C_{\mathrm{B}}^{0} \\ C(\infty, t)=C_{0}\end{array}(t>0)\right.$

Here, $C_{\mathrm{B}}$ represents the concentration of $\mathrm{B}$ in the slag at various positions, while $C_{\mathrm{B}}^{0}$ is the initial concentration at the edge and is regarded as being equal to the concentration of the solute diffusion source (100 ppmw); $C_{0}$ is the concentration of slag in the tube, which is $0 ; D_{\mathrm{s}}$ is the diffusion coefficient; and $t$ is the diffusion time, $t=1200 \mathrm{~s}$. $\operatorname{Erf}(\mathrm{y})$ is the error function.

After taking the definite integral, Eq. (1) can be expressed as

$\frac{C_{\mathrm{B}}-C_{\mathrm{B}}^{0}}{C_{0}-C_{\mathrm{B}}^{0}}=\frac{2}{\sqrt{\pi}} \int_{0}^{x /\left(2 \sqrt{D_{\mathrm{s}}}\right)} \mathrm{e}^{-\lambda^{2}} \mathrm{~d} \lambda$

The right-hand side of Eq. (4) is the error function, which is $\operatorname{erf}(y)$ and $C_{0}=0$. Thus, the equation can be simplified as

$C_{\mathrm{B}}=C_{\mathrm{B}}^{0}\left[1-\operatorname{erf}\left(\frac{x}{2 \sqrt{D_{\mathrm{s}} t}}\right)\right]$

The value of $D$ can therefore be calculated from $C_{\mathrm{B}}, C_{\mathrm{B}}^{0}$, and the table of error for $\operatorname{erf}(\mathrm{y})$.

The diffusion coefficients obtained using Eq. (5) are shown in Fig. 4, in which the slopes of $x^{2}$ and $4 y^{2} t$ are the diffusion coefficients of the four different slag compositions. The accurate values of $C_{\mathrm{B}}$ and $D_{\mathrm{s}}$ are shown in Table 1.

The value of $D_{\mathrm{s}}$ was found to increase from $4.5 \times 10^{-9}$ to $8.46 \times 10^{-9} \mathrm{~m} / \mathrm{s}^{2}$ when the $\mathrm{CaCl}_{2}$ concentration was increased from 10 to $47 \mathrm{~mol} \%$, as shown in Fig. 5. Given that $\mathrm{CaCl}_{2}$ can decrease the viscosity of the slag, the maximum value shows that the solubility of $\mathrm{CaCl}_{2}$ in a $\mathrm{CaCl}_{2}-\mathrm{CaO}-\mathrm{SiO}_{2}$ slag is approximately $50 \%$.

Table 2 compares the diffusion of different elements in various slag systems, revealing that the diffusion of $\mathrm{B}$ in a $\mathrm{CaO}-\mathrm{SiO}_{2}-\mathrm{CaCl}_{2}$ slag is faster than the diffusion of $\mathrm{S}$ in the more viscous $\mathrm{CaO}-\mathrm{SiO}_{2}-\mathrm{Al}_{2} \mathrm{O}_{3}$ slag system. Moreover, the diffusion of $\mathrm{B}$ is faster in molten $\mathrm{Si}$ than in slag, suggesting that the rate-limiting step in the B-removal process may be controlled by the transportation of $\mathrm{B}$ in the slag. However, the diffusion of B in slag can be separated into two distinct steps depending on whether it occurs at interface or surface of the slag. To investigate the diffusion of B in the bulk slag, its mass transfer coefficient in the slag needs to be considered.

\section{Mass Transfer Coefficient of B in Slag}

The positions within the sample used for B analysis in slag and $\mathrm{Si}$ were, as shown in Table 3, at the top of the slag and the bottom of the $\mathrm{Si}$, as the distribution of $\mathrm{B}$ in both was homogeneous. The mass transfer coefficient measurements are also shown in Table 3, wherein the ratio of $\mathrm{B}$ removed to the gas phase was defined as (300- $C_{\mathrm{B}}$ in Si- $\mu \cdot C_{\mathrm{B}}$ in slag)/ 300; $\mu$ being the mass ratio between slag and $\mathrm{Si}(\mu=1,2$, 3 ). It is evident from this that $40-60 \%$ of the $\mathrm{B}$ is 
Table 1 Diffusion coefficients and B concentrations

\begin{tabular}{|c|c|c|c|c|c|c|c|c|c|}
\hline \multicolumn{2}{|c|}{ Distance from the head of the tube $x / \mathrm{mm}$} & \multirow{2}{*}{$\frac{2.0}{74.1}$} & \multirow{2}{*}{$\frac{4.0}{38.1}$} & \multirow{2}{*}{$\frac{6.0}{15.8}$} & \multirow{2}{*}{$\frac{8.0}{4.5}$} & \multirow{2}{*}{$\frac{10}{0.3}$} & \multirow{2}{*}{$\frac{12}{0}$} & \multirow{2}{*}{$\frac{14}{0}$} & \multirow{2}{*}{$\frac{D_{\mathrm{s}}}{8.46 \times 10^{-9} \mathrm{~m}^{2} \mathrm{~s}^{-1}}$} \\
\hline Composition of slag & $C_{\mathrm{B}}(\mathrm{ppmw})$ & & & & & & & & \\
\hline$x_{\mathrm{CaCl}_{2}}: x_{\mathrm{CaO}}: x_{\mathrm{SiO}_{2}}=47: 30: 23$ & $D_{\mathrm{B}}\left(10^{-8} \mathrm{~m}^{2} \mathrm{~s}^{-1}\right)$ & 1.5 & 0.87 & 0.74 & 0.66 & 0.45 & - & - & \\
\hline \multicolumn{2}{|c|}{ Distance from the head of the tube $x / \mathrm{mm}$} & 1.0 & 3.0 & 5.0 & 7.0 & 9.0 & 11 & 13 & $D_{\mathrm{s}}$ \\
\hline Composition of slag & $C_{\mathrm{B}}(\mathrm{ppmw})$ & 85.9 & 48.7 & 27.2 & 15.2 & 6.1 & 0.6 & 0.0 & $8.41 \times 10^{-9} \mathrm{~m}^{2} \mathrm{~s}^{-1}$ \\
\hline$x_{\mathrm{CaCl}_{2}}: x_{\mathrm{CaO}}: x_{\mathrm{SiO}_{2}}=30: 35: 35$ & $D_{\mathrm{B}}\left(10^{-8} \mathrm{~m}^{2} \mathrm{~s}^{-1}\right)$ & 1.3 & 0.75 & 0.86 & 0.98 & 0.95 & 0.66 & - & \\
\hline Composition of slag & $C_{\mathrm{B}}(\mathrm{ppmw})$ & 77.3 & 40.1 & 18.8 & 10.3 & 3.9 & 0.7 & 0.0 & $6.50 \times 10^{-9} \mathrm{~m}^{2} \mathrm{~s}^{-1}$ \\
\hline$x_{\mathrm{CaCl}_{2}}: x_{\mathrm{CaO}}: x_{\mathrm{SiO}_{2}}=20: 40: 40$ & $D_{\mathrm{B}}\left(10^{-8} \mathrm{~m}^{2} \mathrm{~s}^{-1}\right)$ & 0.52 & 0.52 & 0.60 & 0.77 & 0.79 & 0.69 & - & \\
\hline Composition of slag & $C_{\mathrm{B}}(\mathrm{ppmw})$ & 71.6 & 36.1 & 13.0 & 5.6 & 0.8 & 0.0 & 0.0 & $4.50 \times 10^{-9} \mathrm{~m}^{2} \mathrm{~s}^{-1}$ \\
\hline$x_{\mathrm{CaCl}_{2}}: x_{\mathrm{CaO}}: x_{\mathrm{SiO}_{2}}=10: 45: 45$ & $D_{\mathrm{B}}\left(10^{-8} \mathrm{~m}^{2} \mathrm{~s}^{-1}\right)$ & 0.31 & 0.46 & 0.45 & 0.56 & 0 & - & - & \\
\hline
\end{tabular}

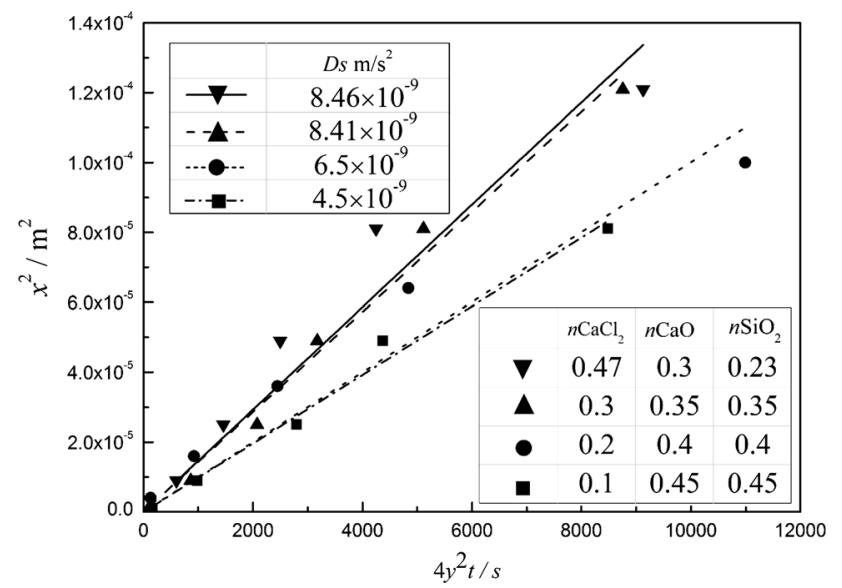

Fig. 4 Diffusion coefficients of four different slags

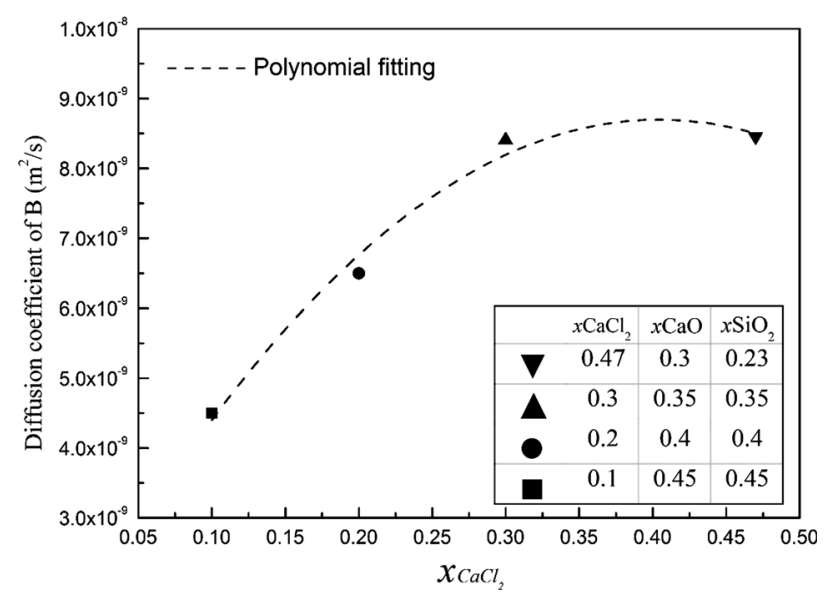

Fig. 5 Change in the diffusion coefficient of B with slag composition

evaporated as gas phase. Moreover, from the mass ratios between Si and slag, we see that the B concentration in the molten Si decreased from 300 to approximately $30 \mathrm{ppmw}$, while the concentration in the slag increased from 0 to approximately 40 ppmw, after $3600 \mathrm{~s}$ at $1723 \mathrm{~K}$. The mass transfer coefficient of B in the slag boundary layer adjacent to $\mathrm{Si}\left(k_{i}\right)$ and the surface $\left(k_{\mathrm{s}}\right)$ will be discussed in the next section.

\section{Kinetics of B Removal Using a $\mathrm{CaO}-\mathrm{SiO}_{2}-\mathrm{CaCl}_{2}$ Slag}

The process of removing $\mathrm{B}$ using a $\mathrm{CaO}-\mathrm{SiO}_{2}-\mathrm{CaCl}_{2}$ slag can be divided into six steps (1) mass transport in $\mathrm{Si}$, (2) chemical reaction at the interface between the slag and $\mathrm{Si}$, (3) mass transport in the slag from the interface to the bulk, (4) mass transport from the bulk to the surface, (5) chemical reaction at the surface, and finally, (6) evaporation from surface to the gas phase.

In Fig. 6, $[\mathrm{B}]_{i},[\mathrm{~B}]_{\mathrm{b}},\left(\mathrm{B}^{3+}\right)_{i},\left(\mathrm{~B}^{3+}\right)_{\mathrm{b}}$, and $\left\{\mathrm{B}^{3+}\right\}_{\mathrm{s}}$ represent the weight concentration of $\mathrm{B}$ in: the molten $\mathrm{Si}$ interface, the bulk molten $\mathrm{Si}$, the interface between $\mathrm{Si}$ and slag, the molten slag bulk, and the surface of the molten slag. The variables $C_{\mathrm{B}_{i}^{3+}}$ and $C_{\mathrm{B}_{\mathrm{b}}^{3+}}$ are the mole concentrations of $\mathrm{B}$ in the interface and bulk of the slag phase, respectively, while $J_{i}$ is the mass flux of $\mathrm{B}$ in step $i$ ( $i=1-6)$. Assuming that the concentration of $\mathrm{B}$ in the bulk slag is homogeneous because of convection but changes over time in the boundary layer at the interface and surface, $C_{\mathrm{B}}$ can be considered a function of $t$ in the boundary layers and the process can be simplified to one of unsteady-state diffusion.

In order to confirm the homogeneity of B in the slag and Si phases, the slag and $\mathrm{Si}$ of sample I-2 was analyzed at various points by ICP. As shown in Fig. 7, this revealed that the B content of the slag was consistently approximately 20.7 ppmw, whereas that of the $\mathrm{Si}$ was much higher at approximately $233.5 \mathrm{ppmw}$. As each value represents an average of three readings, this demonstrates that the distribution of $\mathrm{B}$ in both phases was indeed homogeneous. 
Table 2 Diffusion coefficients of different series

\begin{tabular}{llrc}
\hline Diffusant & Material system (mass \%) & $D\left(\mathrm{~m}^{2} / \mathrm{s}\right)$ & $T(\mathrm{~K})$ \\
\hline $\mathrm{B}$ & $\mathrm{CaO}-\mathrm{SiO}_{2}-\mathrm{CaCl}_{2}(0.15-0.18-0.66)$ & $8.46 \times 10^{-9}$ & 1723 \\
$\mathrm{~S}[13]$ & $\mathrm{CaO}-\mathrm{SiO}_{2}-\mathrm{Al}_{2} \mathrm{O}_{3}(0.52-0.39-0.96)$ & $4.14 \times 10^{-10}$ & 1723 \\
$\mathrm{~B}[12]$ & $\mathrm{Si}$ & $(2.4 \pm 0.7) \times 10^{-8}$ & Melt state \\
$\mathrm{Al}[12]$ & $\mathrm{Si}$ & $(7.0 \pm 3.1) \times 10^{-8}$ & Melt state \\
$\mathrm{P}[12]$ & $\mathrm{Si}$ & $(5.1 \pm 1.7) \times 10^{-8}$ & Melt state \\
\hline
\end{tabular}

Table 3 Experimental conditions and results for the $\mathrm{CaO}-\mathrm{SiO}_{2}-$ $\mathrm{CaCl}_{2}$ slag-silicon reaction at $1723 \mathrm{~K}$

\begin{tabular}{|c|c|c|c|c|c|c|}
\hline No. & $\begin{array}{l}t / \\
k_{\mathrm{s}}\end{array}$ & $\begin{array}{l}\text { Weight } \\
\text { of Si } \\
(\mathrm{g})\end{array}$ & $\begin{array}{l}\text { Weight } \\
\text { of slag } \\
\text { (g) }\end{array}$ & $\begin{array}{l}\text { B } \\
\text { content } \\
\text { of Si } \\
\text { (ppmw) }\end{array}$ & $\begin{array}{l}\text { Change } \\
\text { content of } \\
\mathrm{B} \text { in slag } \\
(\mathrm{ppmw})\end{array}$ & $\begin{array}{l}\text { Ratio of } B \\
\text { removed to } \\
\text { the gas } \\
\text { phase }(\%)\end{array}$ \\
\hline I-1 & 0 & 3.0 & 3.0 & 300 & 0 & 0 \\
\hline I- 2 & 0.3 & & & 233.5 & 20.7 & 15.3 \\
\hline I-3 & 0.6 & & & 196.8 & 43 & 20.1 \\
\hline I-4 & 0.9 & & & 136.4 & 51.8 & 37.3 \\
\hline I-5 & 1.2 & & & 112.3 & 60.1 & 42.5 \\
\hline I-6 & 1.5 & & & 85.7 & 54.5 & 53.3 \\
\hline I-7 & 3.6 & & & 69.6 & 42.7 & 62.6 \\
\hline I-8 & 7.2 & & & 68.1 & 40.3 & 63.9 \\
\hline II-1 & 0 & 3.0 & 6.0 & 300 & 0 & 0 \\
\hline II-2 & 0.3 & & & 225.0 & 14.37 & 15.4 \\
\hline II-3 & 0.6 & & & 173.0 & 20.56 & 28.6 \\
\hline II-4 & 0.9 & & & 126.0 & 33.59 & 35.6 \\
\hline II-5 & 1.2 & & & 109.0 & 39.31 & 37.5 \\
\hline II-6 & 1.5 & & & 83.7 & 44.15 & 42.7 \\
\hline II-7 & 3.6 & & & 76.2 & 57.33 & 36.4 \\
\hline II-8 & 7.2 & & & 65.4 & 38.89 & 52.3 \\
\hline II-9 & 9 & & & 40.4 & 30.07 & 66.5 \\
\hline II-10 & 12 & & & 40.3 & 30.35 & 66.3 \\
\hline III-1 & 0 & 3.0 & 9.0 & 300 & 0 & 0 \\
\hline III-2 & 0.3 & & & 217.6 & 24.5 & 3.0 \\
\hline III-3 & 0.6 & & & 164.8 & 37.3 & 7.8 \\
\hline III-4 & 0.9 & & & 122.7 & 40.7 & 18.4 \\
\hline III-5 & 1.2 & & & 105.5 & 55.1 & 9.7 \\
\hline III-6 & 1.5 & & & 70.3 & 57.2 & 19.4 \\
\hline III-7 & 3.6 & & & 30.8 & 50.4 & 39.3 \\
\hline III-8 & 7.2 & & & 31.6 & 49.2 & 40.3 \\
\hline
\end{tabular}

In step (1) of the B-removal process, if it is assumed that the mass transfer of $\mathrm{B}$ in molten $\mathrm{Si}$ is very fast and that the distribution of $\mathrm{B}$ in molten $\mathrm{Si}$ is homogenous, then the condition $[\mathrm{B}]_{i}=[\mathrm{B}]_{\mathrm{b}}$ is imposed. The diffusion coefficient of $\mathrm{B}$ in molten $\mathrm{Si}\left(D_{\mathrm{B}-\mathrm{Si}}\right)$ can therefore be found as $(2.4 \pm 0.7) \times 10^{-8} \mathrm{~m} / \mathrm{s}^{2}[12]$.

In step (2), the overall interfacial reaction of B removal can be represented by the following reaction:

$[\mathrm{B}]+\frac{3}{4}\left(\mathrm{Si}^{4+}\right)=\left(\mathrm{B}^{3+}\right)+\frac{3}{4} \mathrm{Si}$
Assuming this reaction occurs at the interface between molten $\mathrm{Si}$ and slag, and is in an equilibrium state, the reaction rate can be regarded as being very fast. This is predicated on the fact that Lei Zhang et al. [14] have reported that the mass transfer of boron oxide is the limiting control step in $\mathrm{Na}_{2} \mathrm{SiO}_{3}-\mathrm{CaO}-\mathrm{SiO}_{2}$ slag refining. However, if we assume instead that the chemical reaction is the ratelimiting step, then B transfer in both $\mathrm{Si}$ and slag is faster than the chemical reaction in the boundary layer due to the diffusion coefficients of B in both phases being of the same order. The distribution of $\mathrm{B}$ in the $\mathrm{Si}$ and slag should therefore exhibit a linear relation to distance; however, this is clearly reflected in the curve of the experimental results obtained. Thus, step (2) is not the rate-limiting step.

The process of step (3) is the transfer of B through the slag boundary layer adjacent to $\mathrm{Si}$, as shown in Fig. 6. This means that the mass transfer of $\mathrm{B}$ in the slag, $k_{i}$, can be expressed as

$J_{3}=k_{i}\left(C_{\mathrm{B}_{i}^{3+}}-C_{\mathrm{B}_{\mathrm{b}}^{3+}}\right)$

In step (4), B is transferred through the slag boundary layer at the surface, and according to the definition of mass flux, the mass transfer coefficient of this process $\left(k_{\mathrm{s}}\right)$ can be expressed as

$J_{4}=k_{\mathrm{s}}\left(C_{\mathrm{B}_{\mathrm{s}}^{3+}}-C_{\mathrm{B}_{\mathrm{b}}^{3+}}\right)$

The change in the $C_{\mathrm{B}}$ of the bulk slag $\left(\underline{\mathrm{d}}\left(\mathrm{B}^{3+}\right)_{\mathrm{b}} / \mathrm{d} t\right)$ has a relationship to $\left(J_{3}-J_{4}\right)$, which is

$\frac{\mathrm{d} C_{\left(\mathrm{B}^{3+}\right)_{\mathrm{b}}}}{\mathrm{d} t}=\frac{S}{V_{\text {slag }}}\left(J_{3}-J_{4}\right)$,

where $S$ is the surface area and $V_{\text {slag }}$ is the total volume of the bulk slag. By changing $C_{\mathrm{B}}$ to the weight percentage concentration of $\mathrm{B}\left(\mathrm{B}^{3+}\right)$, and substituting Eqs. (7) and (8) into Eq. (9), we get

$$
\begin{aligned}
\frac{\mathrm{d}\left(\mathrm{B}^{3+}\right)_{\mathrm{b}}}{\mathrm{d} t}= & \frac{\left(J_{3}-J_{4}\right)}{\left(V_{\text {slag }} / S\right) \rho_{\text {slag }}}=\frac{S k_{i}}{m_{\text {slag }}}\left(\left(\mathrm{B}^{3+}\right)_{i}-\left(\mathrm{B}^{3+}\right)_{\mathrm{b}}\right) \\
& -\frac{S k_{\mathrm{s}}}{m_{\text {slag }}}\left(\left(\mathrm{B}^{3+}\right)_{\mathrm{b}}-\left\{\mathrm{B}^{3+}\right\}_{\mathrm{s}}\right),
\end{aligned}
$$

where $\rho_{\text {slag }}$ is the density, $m_{\text {slag }}$ is the mass, and $h$ is the height of the slag $\left(h=V_{\text {slag }} / S\right)$. Considering the partition 
Fig. 6 Profile of B transfer from molten $\mathrm{Si}$ to gas phase
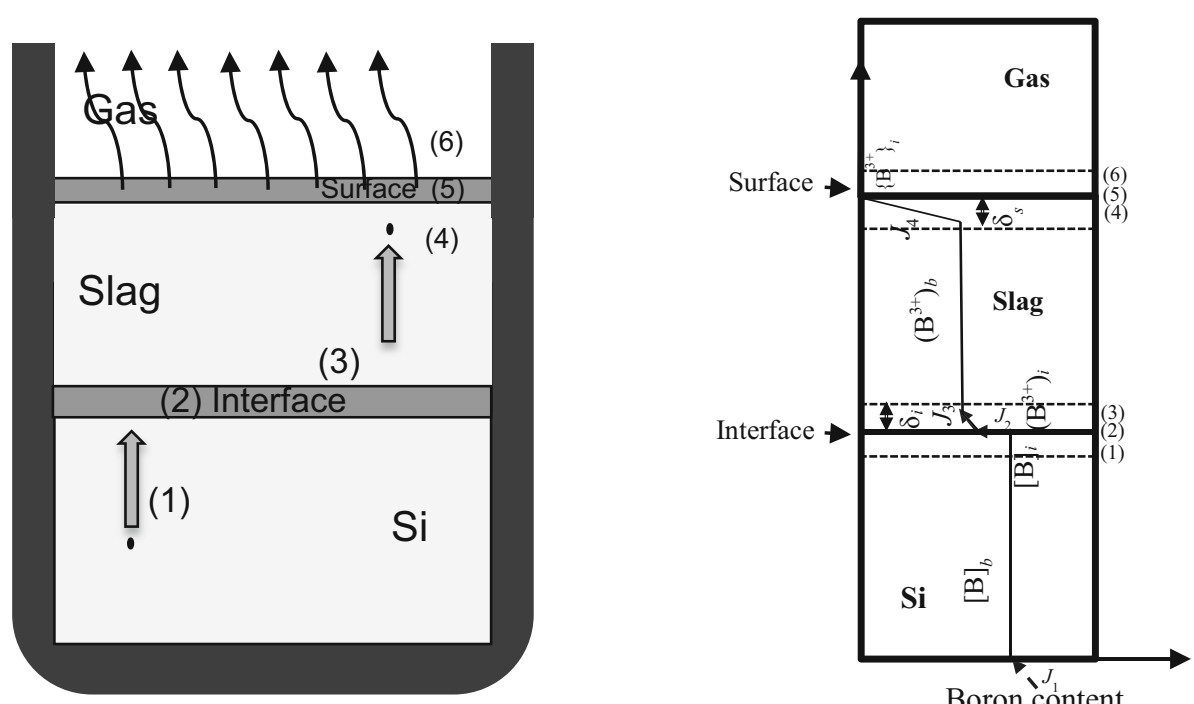

Boron content

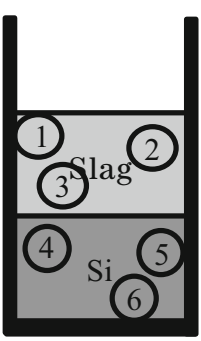

\begin{tabular}{|rc|}
\hline B content & B content \\
Part 1: 20.8 ppmw & Part 4: 232.9 ppmw \\
Part 2: 21.5 ppmw & Part 5: 233.5 ppmw \\
Part 3: 20.1 ppmw & Part 6: 234.1 ppmw \\
\hline
\end{tabular}

Fig. 7 Distribution of B in the slag and Si phase of sample I-2

ratio $\quad L_{\mathrm{B}}=(\mathrm{B})_{i} /[\mathrm{B}]_{i}=(\mathrm{B})_{\mathrm{e}} /[\mathrm{B}]_{\mathrm{e}}=0.64 \quad[11] \quad$ and $[\mathrm{B}]_{i}=[\mathrm{B}]_{\mathrm{b}}$ of the chemical process, evaporation can be assumed to be so fast that the concentration of $\mathrm{B}$ at the surface, $\left\{\mathrm{B}^{3+}\right\}_{\mathrm{s}}$, is zero. Thus, the equation can be simplified to

$\frac{\mathrm{d}\left(\mathrm{B}^{3+}\right)_{\mathrm{b}}}{\mathrm{d} t}=\frac{S k_{i}}{m_{\text {slag }}}\left(L_{\mathrm{B}}[\mathrm{B}]_{\mathrm{b}}-\left(\mathrm{B}^{3+}\right)_{\mathrm{b}}\right)-\frac{S k_{\mathrm{s}}}{m_{\text {slag }}}\left(\mathrm{B}^{3+}\right)_{\mathrm{b}}$

In the same manner, $J_{1}$ can be assumed to be equal to the input flux of $\mathrm{B}$ into molten $\mathrm{Si}$, which is zero. The value of $J_{2}$ is the flux of $\mathrm{B}$ in the interface between the $\mathrm{Si}$ and slag phases, as shown in Fig. 6, and therefore, the change in the $C_{\mathrm{B}}$ of the molten $\mathrm{Si}\left(\mathrm{d}[\mathrm{B}]_{\mathrm{b}} / \mathrm{dt}\right)$ has a relationship with $\left(J_{1}-J_{2}\right)$ as $\frac{\mathrm{d} C_{[\mathrm{B}]_{\mathrm{b}}}}{\mathrm{d} t}=\frac{S}{V_{\text {slag }}}\left(J_{1}-J_{2}\right)$

According to the principle of mass conservation, the flux of B transferred from molten Si to the interface should equal the flux of $\mathrm{B}$ transferred from the interface to the slag bulk; which is to say, $J_{2}=J_{3}$. Because $\left(\mathrm{B}^{3+}\right)_{i}=L_{\mathrm{B}}[\mathrm{B}]_{\mathrm{b}}$ and $J_{1}=0$ in Eq. (12), we therefore get

$$
\begin{aligned}
-\frac{\mathrm{d}[\mathrm{B}]_{\mathrm{b}}}{\mathrm{d} t} & =\frac{J_{3}}{\left(V_{\mathrm{Si}} / S\right) \rho_{\mathrm{Si}}}=\frac{S k_{i}}{m_{\mathrm{Si}}}\left((\mathrm{B})_{i}-\left(\mathrm{B}^{3+}\right)_{\mathrm{b}}\right) \Rightarrow-\frac{\mathrm{d}[\mathrm{B}]_{\mathrm{b}}}{\mathrm{d} t} \\
& =\frac{S k_{i}}{m_{\mathrm{Si}}}\left(L_{\mathrm{B}}[\mathrm{B}]_{\mathrm{b}}-\left(\mathrm{B}^{3+}\right)_{\mathrm{b}}\right)
\end{aligned}
$$

Assuming $y=\left(\mathrm{B}^{3+}\right)_{\mathrm{b}}$ and $x=[\mathrm{B}]_{\mathrm{b}}$, the first-order ordinary differential equation system for the mass transfer of $\mathrm{B}$ within bulk melts can be obtained from Eq. (11) and (13) as

$$
\left\{\begin{array}{l}
\frac{\mathrm{d} y}{\mathrm{~d} t}=\frac{S k_{i} L_{\mathrm{B}}}{m_{\mathrm{slag}}} x-\frac{S\left(k_{i}+k_{\mathrm{s}}\right)}{m_{\mathrm{slag}}} y \\
\frac{\mathrm{d} x}{\mathrm{~d} t}=-\frac{S L_{\mathrm{B}} k_{i}}{m_{\mathrm{Si}}} x+\frac{S k_{i}}{m_{\mathrm{Si}}} y
\end{array}, \text { when } t=0, x=x_{0}, y=0\right.
$$

Solving Eq. (14) and assuming

$$
\left\{\begin{array}{c}
\mathrm{A}=\left(-k_{i}-k_{\mathrm{S}}-k_{i} L_{\mathrm{B}}-\sqrt{-4 k_{i} k_{\mathrm{S}} L_{\mathrm{B}}+\left(k_{i}+k_{\mathrm{S}}+k_{i} L_{\mathrm{B}}\right)^{2}}\right) / 2(m / S) \\
\mathrm{B}=\left(-k_{i}-k_{\mathrm{s}}-k_{i} L_{\mathrm{B}}+\sqrt{-4 k_{i} k_{\mathrm{S}} L_{\mathrm{B}}+\left(k_{i}+k_{\mathrm{s}}+k_{i} L_{\mathrm{B}}\right)^{2}}\right) / 2(m / S) \\
\mathrm{C}=\sqrt{-4 k_{i} k_{\mathrm{S}} L_{\mathrm{B}}+\left(k_{i}+k_{\mathrm{S}}+k_{i} L_{\mathrm{B}}\right)^{2}}
\end{array}\right.
$$


we get a general solution for $x$ and $y$ as

$$
\left\{\begin{array}{rl}
x(t)= & \frac{1}{2 C}\left(-\mathrm{e}^{\mathrm{A} t} k_{i}+\mathrm{e}^{\mathrm{B} t} k_{i}-\mathrm{e}^{\mathrm{A} t} k_{\mathrm{s}}+\mathrm{e}^{\mathrm{B} t} k_{\mathrm{s}}+\mathrm{e}^{\mathrm{A} t} k_{i} L_{\mathrm{B}}\right. \\
& \left.-\mathrm{e}^{\mathrm{B} t} k_{i} L_{\mathrm{B}}+\mathrm{e}^{\mathrm{A} t} C+\mathrm{e}^{\mathrm{B} t} C\right) x_{0} \\
y(t)= & -\frac{1}{C}\left(\mathrm{e}^{\mathrm{A} t}-\mathrm{e}^{\mathrm{B} t}\right) k_{i} L_{\mathrm{B}} x_{0}
\end{array},\right.
$$

where $[\mathrm{B}]_{0}=300 \mathrm{ppmw}, \quad \rho_{\text {slag }}=2.01 \mathrm{~g} / \mathrm{cm}^{3}, \quad \rho_{\mathrm{Si}}=$ $2.57 \mathrm{~g} / \mathrm{cm}^{3}, S=3.14 \mathrm{~cm}^{2}$, and $L_{\mathrm{B}}=0.64$. Because the initial content of $\mathrm{B}$ in the slag is $10.9 \mathrm{ppmw}$, the change in the $\mathrm{B}$ content of the slag is the difference between the actual content and 10.9 ppmw, as shown in Table 3. In Eq. (15), $x$ and $y$ are variables related to $t$, while $k_{i}$ and $k_{\mathrm{s}}$ are the only unknown constants. Thus, $k_{i}$ and $k_{\mathrm{s}}$ were obtained from the three sets of data displayed in Table 3 via a nonlinear regression analysis method using 1st Opt software. These results are shown in Fig. 8.

Figure 8 shows that the fitted values from the model for $k_{i}\left(1.91 \times 10^{-5} \mathrm{~m} / \mathrm{s}\right)$ and $k_{\mathrm{s}}\left(2.50 \times 10^{-5} \mathrm{~m} / \mathrm{s}\right)$ are reasonable and agree with all three series results in the molten $\mathrm{Si}$ and slag, as is also shown in Table 4.

In step (5), the reaction between the slag and gas phase is assumed to occur at the surface in accordance with the following reaction $[11,15]$ :

$\mathrm{BO}_{1.5}(l)+\frac{1}{2} \mathrm{CaCl}_{2}(l)=\operatorname{BOCl}(g)+\frac{1}{2} \mathrm{CaO}(s)$

As this means that the reaction rate is very rapid at high temperatures, step (5) is not the rate-limiting step. In the case of step (6), the diffusion of $\mathrm{BOCl}$ gas in an Ar atmosphere is likely to be very fast, and therefore, step (6) also cannot be the rate-limiting step.

The thickness of the boundary layers of slag adjacent to Si $\left(\delta_{i}\right)$ and at the surface $\left(\delta_{\mathrm{s}}\right)$ can be calculated by

$\delta_{i}=D_{\mathrm{s}} / k_{3} \delta_{s}=D_{\mathrm{s}} / k_{4}$

Using (17), the different values of $\delta_{i}$ and $\delta_{\mathrm{s}}$ for different mass ratios of slag and $\mathrm{Si}$ were calculated. As shown in Table 4 , this found that the value of $k_{i}\left(1.91 \times 10^{-5} \mathrm{~m} / \mathrm{s}\right)$ is slightly lower than that of $k_{\mathrm{s}}\left(2.50 \times 10^{-5} \mathrm{~m} / \mathrm{s}\right)$, which means that the rate-limiting step is controlled by both the boundary layer adjacent to $\mathrm{Si}$ and that at the surface. However, it is the former that has the greatest influence, because the thickness of the boundary layer of slag in the $\mathrm{Si}$ /slag interface $(0.44 \mathrm{~mm})$ is thicker than that at the surface $(0.34 \mathrm{~mm})$.
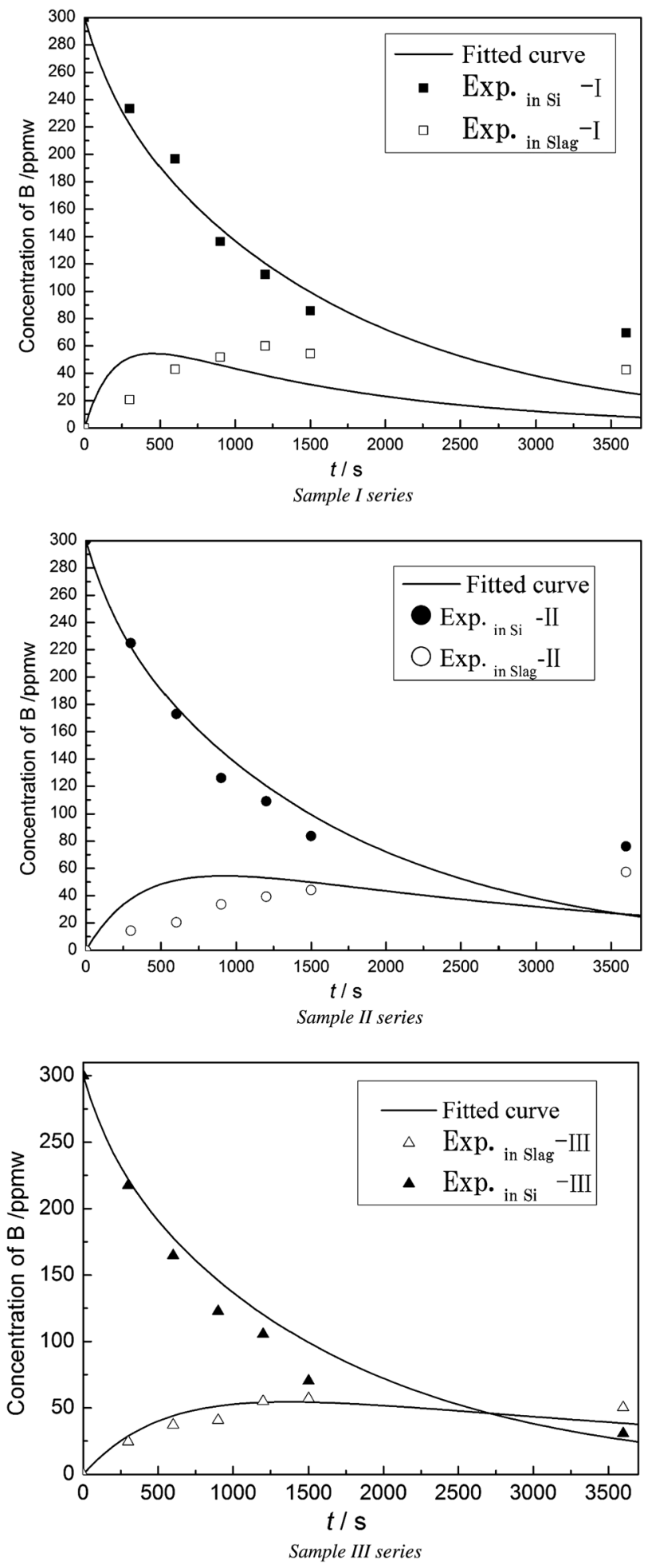

Fig. 8 Change in $\left(\mathrm{B}^{3+}\right)_{b}$ and $[\mathrm{B}]_{b}$ with time 
Table $4 k_{i}, k_{s}, \delta_{i}$, and $\delta_{s}$ with different mass ratios between slag and molten $\mathrm{Si}$

\begin{tabular}{llllll}
\hline$D_{\mathrm{s}}\left(\mathrm{m}^{2} / \mathrm{s}\right)$ & $k_{i}(\mathrm{~m} / \mathrm{s})$ & $k_{\mathrm{s}}(\mathrm{m} / \mathrm{s})$ & $\delta_{i}(\mathrm{~mm})$ & $\delta_{\mathrm{s}}(\mathrm{mm})$ & Correlation coefficient \\
\hline $8.46 \times 10^{-9}$ & $1.91 \times 10^{-5}$ & $2.50 \times 10^{-5}$ & 0.44 & 0.34 & 0.97 \\
\hline
\end{tabular}

\section{Conclusion}

To investigate the kinetics of the removal of $\mathrm{B}$ by evaporation using different compositions of $\mathrm{CaO}-\mathrm{SiO}_{2}-$ $\mathrm{CaCl}_{2}$ slags, a model for the transfer of $\mathrm{B}$ from $\mathrm{Si}$ to molten slag by diffusion and its evaporation as a gas phase was established. The mass transfer and diffusion coefficients of $\mathrm{B}$ in the slag were measured at $1723 \mathrm{~K}$ for different times and different mass ratios between the slag and $\mathrm{Si}$. In addition, the rate controlling steps were also investigated based on the kinetics model and the calculated values of $k_{\mathrm{s}}$ and $D_{\mathrm{s}}$. Thus, from this study, the following conclusions have been drawn.

(1) The diffusion coefficient of $\mathrm{B}$ in slag $\left(D_{\mathrm{s}}\right)$ is $8.46 \times 10^{-9} \mathrm{~m} / \mathrm{s}^{2}$, which means the rate of step (3) is slower than that of $\mathrm{B}$ diffusion in $\mathrm{Si}$ $\left[(2.4 \pm 0.7) \times 10^{-8} \mathrm{~m} / \mathrm{s}^{2}\right]$. Thus, unlike other elements such as $\mathrm{Al}, \mathrm{Ca}, \mathrm{Mg}$, and $\mathrm{P}$, the rate-limiting step of $\mathrm{B}$ diffusion in $\mathrm{CaO}-\mathrm{SiO}_{2}-\mathrm{CaCl}_{2}$ slag refining is controlled by the transfer of $\mathrm{B}$ in the slag.

(2) With regards to the reaction rate, $\mathrm{B}$ oxidation (step 2), B oxychlorination (step 5), and the evaporation of $\mathrm{BOCl}$ from the surface (step 6) all occur very quickly, and therefore, they cannot be considered rate-limiting steps. The mass transfer coefficient of $\mathrm{B}$ in slag was therefore measured and found to be $1.91 \times 10^{-5} \mathrm{~m} / \mathrm{s}$ for the transfer from the slag interface to the bulk slag, and $2.50 \times 10^{-5} \mathrm{~m} / \mathrm{s}$ for the transfer from the bulk slag to the surface.

(3) The rate-limiting step in the removal of B from Si by slag refining is the transfer of B at both the boundary layer adjacent to $\mathrm{Si}$ and at the surface of the slag. However, the former of these has the greater influence, because the thickness of the $\mathrm{Si} / \mathrm{slag}$ interface $(0.44 \mathrm{~mm})$ is greater than the boundary at the surface $(0.34 \mathrm{~mm})$.

\section{References}

1. Ma X, Yoshikawa T, Morita K (2013) Removal of boron from silicon-tin solvent by slag treatment. Metall Mater Trans B 44:528-533

2. Ma X, Yoshikawa T, Morita K (2013) Si growth by directional solidification of $\mathrm{Si}-\mathrm{Sn}$ alloys to produce solar-grade $\mathrm{Si}$. J Cryst Growth 377:192-196

3. Yuge N, Hanazawa K, Kato Y (2004) Removal of metal impurities in molten silicon by directional solidification with electron beam heating. Metall Mater Trans B 45:850-857

4. Martorano M, Neto JF, Oliveira T, Tsubaki T (2011) Macrosegregation of impurities in directionally solidified silicon. Metall Mater Trans A 42:1870-1886

5. Ma X, Yoshikawa T, Morita K (2012) Phase relations and thermodynamic property of boron in the silicon-tin melt at $1673 \mathrm{~K}$. J Alloy Compd 529:12-16

6. Li Y, Tan Y, Li J, Xu Q, Liu Y (2014) Effect of Sn content on microstructure and boron distribution in Si-Al alloy. J Alloy Compd 583:85-90

7. Suzuki K, Kumagai T, Sano N (1992) Removal of boron from metallurgical-grade silicon by applying the plasma treatment. ISIJ Int 32:630-634

8. Nakamura N, Baba H, Sakaguchi Y, Kato Y (2004) Boron removal in molten silicon by a steam-added plasma melting method. Metall Mater Trans B 45:858-864

9. Ikeda T, Maeda M (1992) Purification of metallurgical silicon for solargrade silicon by electron beam button melting. ISIJ Int 32:635-642

10. Zheng S, Engh TA, Tangstad M, Luo XT (2011) Numerical simulation of phosphorus removal from silicon by induction vacuum refining. Metall Mater Trans A 42:2214-2225

11. Wang Y, Ma X, Morita K (2014) Evaporation removal of boron from metallurgical-grade silicon using $\mathrm{CaO}-\mathrm{CaCl}_{2}-\mathrm{SiO}_{2}$ slag. Metall Mater Trans B 45:334-337

12. Kodera H (1963) Diffusion coefficients of impurities in silicon melt. Jpn J Appl Phys 2:212

13. Viswanathan LMNN, Seetharaman S (2012) Evaluating the chemical diffusion coefficient of sulfur in slag by metal analysis: model concept and experiments. 9th international conference on molten slags, fluxes and salts

14. Zhang L, Tan Y, Li J, Liu Y, Wang D (2013) Study of boron removal from molten silicon by slag refining under atmosphere. Mater Sci Semicond Process 16(6):1645-1649

15. Bjerke H (2012) Removal of boron from silicon by slag treatment and by evaporation of boron from slag in hydrogen atmosphere. Doctoral dissertation, Norwegian University of Science and Technology, p 35 